\title{
EFFECT OF CARRIER GAS FLOW RATE AND COLUMN TEMPERATURE ON THE SUITABILITY PARAMETERS OF GC-ECD FOR SF 6 MEASUREMENT
}

\author{
ZUAS, Oman ${ }^{*}$ \\ Gas Analysis Laboratory (GasAL), Metrology in Chemistry (MiC) Research Group, Research Centre for \\ Metrology-Indonesian Institute of Sciences (RCM-LIPI), Kawasan PUSPIPTEK Building No. 456, Serpong, \\ 15314, Tangerang Selatan, Indonesia \\ (phone: +62 217560 533; fax: +62 217560 064) \\ * Corresponding author \\ e-mail: oman.zuas@lipi.go.id
}

Received 03 January 2017; received in revised form 03 April 2017; accepted 20 June 2017

\section{RESUMO}

O teste de adequação do sistema de um CG é essencial para verificar sua adequação para a aplicação pretendida. A CG sempre usa uma temperatura de gás carreador e coluna, o que pode afetar seus parâmetros de adequação. Este estudo tem como objetivo avaliar os efeitos da taxa de fluxo de gás carreador (FLRT) e da temperatura da coluna (CLTP) nos parâmetros de adequação do sistema (SSP) da CG-DCE para medição SF 6 como tempo de retenção / $t_{R}$, fator de resposta / $R F$, número de pratos teóricos / $N$, e fator assimétrico / As. $A$ avaliação foi conduzida através da análise cuidadosa do cromatograma $\mathrm{SF}_{6} \mathrm{e}$ os dados obtidos foram utilizados para calcular os valores $t_{R}, R, N$ e As. Verificou-se que o $t_{R}$ aumenta linearmente $\left(R^{2}=0,9978\right)$ aumentando o FLRT, mas diminui linearmente $\left(R^{2}=0,9991\right)$ ao aumentar o CLTP. O RF diminui linearmente $\left(R^{2}=0,9939\right)$ ao aumentar o FLRT. Curiosamente, o RF foi afetado pelo CLTP com $2^{\mathrm{a}}$ tendência da ordem polinomial $\left(R^{2}=0,9949\right)$. O N aumenta linearmente $\left(R^{2}=0,9404\right)$ aumentando o FLRT, mas o $N$ foi afetado pelo CLTP com $2^{a}$ tendência da ordem polinomial $\left(R^{2}=0,9769\right)$. O As foi encontrado para aumentar ligeiramente com FLRT $\left(R^{2}=0,1288\right)$, enquanto $\circ A_{s}$ foi afetado pela TC com $2^{a}$ tendência da ordem polinomial $\left(R^{2}=0,9778\right)$. Estes resultados estão em bom acordo com os estudos anteriores do SSP.

Palavras-chave: Testes de adequação, cromatografia gasosa, detector de captura de elétrons, detector seletivo, hexafluoreto de enxofre.

\section{ABSTRACT}

System suitability testing of a GC is essential to verify its suitability for intended application. The GC always uses a carrier gas and column temperature, which may impact on its suitability parameters. This study is aimed to evaluate the effects of carrier gas flow rate (FLRT) and column temperature (CLTP) on the system suitability parameters (SSP) of GC-ECD for $\mathrm{SF}_{6}$ measurement such as retention time/t $t_{R}$, response factor/RF, theoretical plate numbers $/ N$, and asymmetric factor $/ A_{s}$. The evaluation was conducted by carefully profiling the $\mathrm{SF}_{6}$ chromatogram and the data obtained were used to calculate the $t_{R}, R F, N$, and $A_{s}$ values. It was found that the $t_{R}$ increases linearly $\left(R^{2}=0.9978\right)$ by increasing the FLRT, but decreases linearly $\left(R^{2}=0.9991\right)$ by increasing the CLTP. The $R F$ decreases linearly $\left(R^{2}=0.9939\right)$ by increasing the FLRT. Interestingly, the $R F$ was affected by the CLTP with $2^{\text {nd }}$ polynomial order trend $\left(R^{2}=0.9949\right)$. The $N$ increases linearly $\left(R^{2}=0.9404\right)$ by increasing the FLRT but the $N$ was affected by the CLTP with $2^{\text {nd }}$ polynomial order trend $\left(R^{2}=0.9769\right)$. The $A_{s}$ was found to increase slightly with FLRT $\left(R^{2}=0.1288\right)$, while the $A_{s}$ was affected by the CT with $2^{\text {nd }}$ polynomial order trend $\left(R^{2}=0.9778\right)$. These results are in a good agreement with previous SSP studies.

Keywords: Suitability tests, gas chromatography, electron capture detector, selective detector, sulfur hexafluoride. 


\section{INTRODUCTION}

Ever since its discovery in early 1900s (Balaban, 2011), gas chromatography (GC) technique has made significant contribution in the field of chemical analysis. High sensitivity, good selectivity, and prominent detectability of the target analyte in a complex sample are predominantly reasons for choosing the GC among other related analytical techniques (Pfannkoch, et al., 2005, Wu, et al., 2014). In a practical GC experiment, the detection of target analyte in the mixture eluted from the column is conducted by device so called detector. Based on its detectability characteristic, the GC detector is grouped into two main categories i.e., universal and selective detector (Colon and Baird, 2004). The universal detector defines to any detector that able to response a wide range of analytes (chemical compounds), while a selective detector defines to any detector that has an ability to response analytes with specific elemental, molecular, or physical properties (Yuwono and Indrayanto, 2005). The former detector category may include flame ionization detector/FID (universal to carbon-containing analytes) and thermal conductivity detector/TCD (universal to any analytes having difference in thermal conductivity relative to carrier gas) (Deng, Yang et al. 2005, Haskin and Edwards 2013). The later category may include nitrogen phosphorus detector/NPD (detector which selective to nitrogen or phosphorus-containing analytes), flame photometric detector/FPD (selective to certain analytes containing phosphorus or sulfur element), and electron capture detector/ECD (selective to any analytes containing electronegative groups) (Yuwono and Indrayanto. 2005; Basuri et al., 2016, Bordagaray et al., 2016).

Among the aforementioned detectors, the ECD might be one of the most common used GC's detector and it can be found easily in both government and private laboratories worldwide. The ECD is known very sensitive for the detection of electron-absorbing molecules (with high electronegativity property) such as halogenated analytes, with detection sensitivity near one part per billion (ppb) level (Jin et al., 2012; Jong et al., 2014). Nowadays, the applications of the GC-ECD for the detection of halogenated-containing analytes have been reported by numerous analytical laboratory practitioners, by which the types of the analyzed sample are originated from diverse areas such as agricultural, soil, water, air and industrial products (Fattahi et al., 2007; Banghui et al., 2009; HunterJr et al., 2010; Yu et al.; 2012).

In the last two decades, increasing the GHGs levels in atmospheric is a worldwide concern. The GHGs could possibly increase the global warning effect because its ability to trap the heat in atmosphere lead to increase the climate change phenomenon (Blasing, 2016). Among the GHG species listed in Kyoto Protocol, the $\mathrm{SF}_{6}$ is probably the longest lifetimes species in atmosphere (ca. 3200 years) with very high global warming potentials (GWPs) at about 23,900 times stronger than $\mathrm{CO}_{2}$ species and thus plays important role in climate forcing (Fang, $\mathrm{Hu}$ et al. 2013, Blasing T.J. 2016). Naturally, atmospheric $\mathrm{SF}_{6}$ exists in very low concentration (ca. sub-ppb level), owing to its anthropogenic origin (Santella et al., 2012; Jong et al., 2015). Therefore, the use of a very sensitive detection instrument, such as the GC-ECD, for the detection of the atmospheric $\mathrm{SF}_{6}$ has been widely applied.

For the GC equipped with any type of detector, its running process is involving the use of both carrier gas and column as mobile phase and stationary phase, respectively. The carrier gas allows for passing through and separating the target analyte molecule on the column. Soundly, therefore, both carrier gas and column conditions may become two distinct factors affecting the separation process. With regards to the effect of carrier gas and column conditions on the GC analytical parameters, some studies have been reported previously. Sevcik (1976) reported that a flow rate difference of the carrier gas induces detector sensitivity on the GC measurement. Scott (1996) and Bebbrecht (1997) identified that the peak height of the GC is highly dependent of the change of column temperature. The effects of general operating conditions of the GC on the measurement parameters has been weel-summarized by Barwick (1999). However, study related to the effect of the operating conditions on the suitability parameter of the GC for a specific target analyte(s) is still promising to be directed.

This paper reports an investigation result on the study regarding the effect of flow rate of carrier gas and column temperature on the suitability parameters of GC-ECD for $\mathrm{SF}_{6}$ measurement. Four suitability parameters were assessed including retention time $\left(t_{R}\right)$, response factor (RF), theoretical plate numbers $(N)$, and 
asymmetric factor $\left(A_{s}\right)$. The data obtained may useful for understanding such effect; hence, some actions to reduce the uncertainty of the measurement can be taken for assuring the reliability of the analytical results.

\section{THEORITICAL}

\subsection{Retention time $\left(t_{R}\right)$}

The chromatography's retention time $\left(t_{R}\right)$, as schematically shown in Fig. 1, is referred to the time required for a molecule of a target analyte to pass through the chromatography column (USP29, 2016). The retention time of the same target analyte may vary from time to time during measurement process due to a number of reasons such as poor column temperature repeatability, poor injection technique, and instability of the carrier gas flow rate (Barwick, 1999).

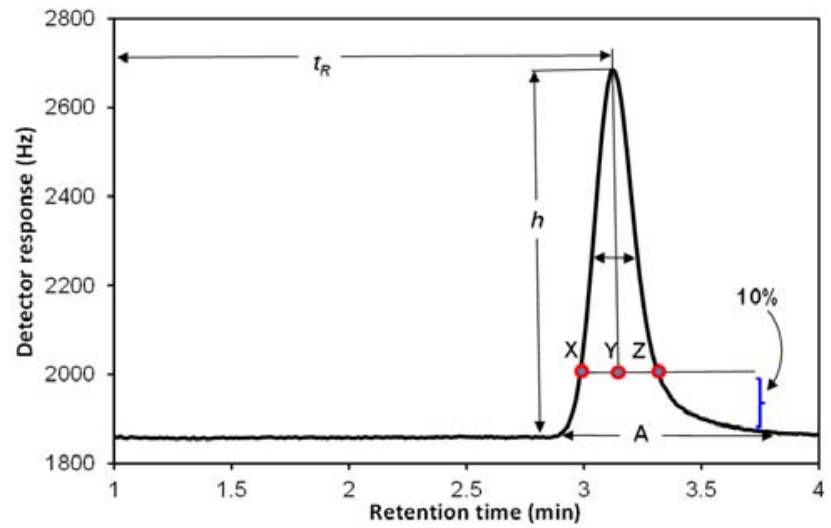

Figure 1. A schematic diagram of a typical GC chromatogram $\left(t_{R}=\right.$ retention time, $h=$ peak height, and $A=$ peak area).

\subsection{Response factor (RF)}

Response factor of the chromatography is a measure of the relative response of target analyte being analyzed compared to its detector response (Dettmer-Wilde and Engewald, 2014). The response of the detector is displayed as a peak. The most common formula to quantify the response factor of a target analyte is expressed as in Eq. 1.

Response factor $(R F)=\frac{A}{C}$

where $A$ is peak area of the target analyte and $C$ is concentration of analyte being analyzed. In chromatography study, peak area $(A)$ is referred to the area enclosed between the peak and the baseline (Dettmer-Wilde and Engewald, 2014). Experimentally, the target analyte passed through from the column to a detector is measured. The measured analyte in the form of signal is integrated over time. In a modern chromatography system, quantitation is performed by feeding the detector signal into a digital recorder. The recorder produces a typical chromatogram (plot of signal versus time) (Gordon, 2013). The peak area of a target analyte may be determined by integrating manually or automatically, with the beginning and ending points of the peaks are indicated. The peak area $(A)$ of the target analyte (Fig. 1) is calculated by using Eq. 2 .

Peak area $(A)=h_{\max } \times W_{0.5}$

where $h$ is peak height maxima and $W$ is peak width (See Fig. 1).

\subsection{Theoretical Plate Numbers (N)}

Chromatography instruments measure the column performance and efficiency in terms of the number of theoretical plates $(\mathrm{N})$ ) and it is calculated by using Eq. 3) (McNair and Miller, 2011).

Theoretical plate numbers

$$
(N)=16\left(\frac{t_{R}}{W}\right)^{0.5}
$$

where $t_{R}$ is retention time of the target analyte (See Fig. 1). From the formula, it can be estimated that narrower peak widths at longer retention times may result a higher plate numbers.

\subsection{Asymmetric Factor $\left(A_{s}\right)$}

Peak asymmetry characteristic of a target analyte being analyzed is highly depended on several factors such as properties of the column, the sample matrix, and the analyte itself. Asymmetry factor $\left(A_{s}\right)$ is defined as the distance from the center line of the peak to the back slope $(Y Z)$ divided by the distance from the center line of the peak to the front slope $\left(X Y_{10 \%}\right)$, with all measurements made at $10 \%$ of the maximum peak height (Fig. 1). The equation for the calculation of $A_{s}$ is given in Eq. 4 (McNair and Miller, 2011). 
Asymmetric factor $\left(A_{s}\right)=\frac{Y Z}{X Y_{10 \%}}$

where $Y Z$ is back slope and $X Y$ is front slope of the analyte peak (See Fig. 1).

\section{MATERIALS AND METHODS}

\subsection{Preparation of Gas Standard}

A secondary standard of $\mathrm{SF}_{6}(158.92 \mathrm{ppb})$ in Helium $(\mathrm{He})$ as a matrix was prepared from a parent standard $\mathrm{SF}_{6}(10 \mathrm{ppm})$ purchased from Sarana Indotim Imex Indonesia. The preparation was conducted by the dilution technique in accordance with the ISO Guide: 6142-preparation of gas mixture-gravimetric method (ISO, 2015). Secondary gas standard is referred to a gas standard that is related to primary standard through analysis.

\subsection{GC Instrumentation and Operating Conditions}

The measurement of $\mathrm{SF}_{6}$ was conducted by using an Agilent 7890B GS system equipped with an electron capture detector (ECD, Agilent Technologies, Santa Clara, CA) was used. In a typical work, separation of $\mathrm{SF}_{6}$ was achieved using Hayesep Q packed columns (HQ 1,2 m, 1/8 inch OD, UM, Agilent Technology G3591-82519, precolumn) and a Hayesep $\mathrm{R}$ packed column (HR $1.8 \mathrm{~m}, 1 / 8$ inch OD, Agilent Technology, G3591-82102, main column). Table 1 lists the operating conditions of the GC-ECD under this study. The carrier gas was purified before entering the column using hydrocarbon filter (activated charcoal, Agilent Technology, USA).

Table 1. Operating conditions of the GC-ECD

\begin{tabular}{|c|c|}
\hline Parameter & GC- $\mu E C D$ \\
\hline Target analyte & $\mathrm{SF}_{6}$ \\
\hline Carrier gas flow rate & $\mathrm{N}_{2}$ at $21.5 \mathrm{ml} / \mathrm{min}$ \\
\hline Injector temperature & $250^{\circ} \mathrm{C}$ \\
\hline Loop & SS tube, $1 \mathrm{ml}$ \\
\hline Column temperature & Isothermal, $72^{\circ} \mathrm{C}$ \\
\hline $\begin{array}{l}\text { Detector } \\
\text { temperature }\end{array}$ & $350^{\circ} \mathrm{C}$ \\
\hline Reference flow rate & \\
\hline $\begin{array}{l}\text { Make-up gas flow } \\
\text { rate }\end{array}$ & $\begin{array}{l}5 \% \quad \mathrm{CH}_{4}-95 \% \text { Ar } \quad(2 \\
\mathrm{ml} / \mathrm{min})\end{array}$ \\
\hline Injection mode & Splitless \\
\hline $\begin{array}{l}\text { Signal source / data } \\
\text { rate / minimum peak } \\
\text { width }\end{array}$ & $\mu \mathrm{ECD} / 5 \mathrm{~Hz} / 0.04 \mathrm{~min}$ \\
\hline
\end{tabular}

\subsection{System Suitability Test Procedures}

For introducing the $\mathrm{SF}_{6}$ secondary gas standard from aluminum cylinder into the GC system and to maintenance the gas rate at constant flow (100 $\mathrm{ml} / \mathrm{min})$, a Brooks 5890E mass flow controller (Brooks Instrument, Hatfield, USA) was used. The mass flow controller system was installed just before the injection system consisted of a stainless steel tubing having 1/16 inch in diameters up to the loop inlet, a $1 \mathrm{ml}$ stainless steel loop (Agilent, CA, USA). The measurement process was conducted under GC parameter as listed in Table 1. The output signal was monitored using installed software (OpenLAB CDS Chemstation Edition Rev. C.01.07, Agilent Technology, USA), on a HP personal computer (HP ProDesk 490 G2 MT, Hawlett-Packard Company). The measurement data was estimated by automated integration of the area under the resolved chromatographic profile.

\subsection{Evaluation of System Suitability}

The data for the system suitability evaluation was obtained by injecting at least five replications of the $\mathrm{SF}_{6}$ secondary gas standard into the GC-ECD with percentage relative standard deviation (\%RSD) was set to 0.5 as a maximum value. Profile of generated chromatogram of the $\mathrm{SF}_{6}$ from every injection was carefully examined to investigate the effect of both carrier gas and column temperature on the system suitability of GC-ECD. The data obtained were then used to calculate the suitability parameters including retention time $\left(t_{R}\right)$, response factor $(R F)$, numbers of theoretical plate $(N)$, and asymmetric factor $\left(A_{s}\right)$.

\section{RESULTS AND DISCUSSION}

In $\mathrm{SF}_{6} \quad$ measurement principle, strong electronegative $\mathrm{SF}_{6}$ molecules in the $\mathrm{GC}$ effluent passing through the column and then the $\mathrm{SF}_{6}$ molecules capture free electrons resulted from a collision between electron emitter (radionuclide ${ }^{63} \mathrm{Ni}$ ) and carrier gas molecules. The capturing of the electron reduces the current and it is recorded as a positive peak (AP, 2016). In practice, checking the GC system is extremely importance before conducting a measurement of analyte in samples so that effectiveness of the final operating system can be assured (USP29, 2016). 
In this study, checking the system suitability was conducted by examining the effect of operating of the GC-ECD for the measurement of $\mathrm{SF}_{6}$. For this purpose, the $\mathrm{SF}_{6}$ standard (158.92 ppb) was chromatographed on Hayesep $\mathrm{R}$ packed column. The first experiment was performed by examining the effect of flow rate of carrier gas, followed by the second experiment on investigation the effect of column temperature on the aforementioned suitability parameters. The effects of carrier gas and column temperature on the system suitability parameters investigated are graphically presented and discussed.

\subsection{Retention Time $\left(t_{R}\right)$}

Figure $2 \mathrm{a}$ and $2 \mathrm{~b}$ display the dependency of the retention time (hereinafter denoted as $t_{R}$ ) of $\mathrm{SF}_{6}$ on the flow rate of carrier gas and column temperature, respectively. In the field of GC technique, the flow rate of carrier gas (mobile phase) can be used to indicate how fast the carrier gas is carrying the target analyte through the column, meaning that the lower flow rate of carrier gas will have the longer $t_{R}$ and vice versa (Dettmer-Wilde and Engewald, 2014). Interestingly, from Fig. 2a it can be clearly observed that the $t_{R}$ of $\mathrm{SF}_{6}$ increases linearly $\left(R^{2}\right.$ $=0.9978$ ) by increasing the rate of carrier gas flow, indicating that increased the flow rate would not decrease the $t_{R}$ of the $\mathrm{SF}_{6}$. This phenomenon was not found in agreement with previous reports (El-Naggar, 2013; Zuas and Budiman, 2016), where the $t_{R}$ of carbon-based compounds decreased with increasing the rate of carrier gas flow because a faster flow rate of the carrier gas may decrease the time of vaporized molecules spend in the column. Under experimental condition of this study for the $\mathrm{SF}_{6}$ measurement, it may attributable to the strong interaction between $\mathrm{SF}_{6}$ (non-polar molecule) target component and the stationary phase (column), leading to increase the $t_{R}$ by increasing the flow rate of carrier gas. Nevertheless, in general, the $t_{R}$ in a GC separation process is controllable, meaning that a suitable $t_{R}$ for the target analyte can be possibly attained by adjusting the flow rate of carrier gas (Zuas and Budiman, 2016).

Figure $2 b$ depicts the effect of column temperature on the $t_{R}$ of $\mathrm{SF}_{6}$. It can be seen from Fig. $2 \mathrm{~b}$ that the $t_{R}$ of the $\mathrm{SF}_{6}$ decreases by increasing the column temperature $\left(R^{2}=0.9991\right)$, showing that higher temperature of the column lead to shorter $t_{R}$ of $\mathrm{SF}_{6}$. This finding implies that the ability of target analyte to interact with the stationary phase at higher column temperature is lower (Bruner, 1993).

In general, if the compound does not interact with the stationary phase, the $t_{R}$ will decrease making the component stay in the gas phase but this can result in a poor separation (especially for sample containing multi components). On the other hand, the components should interact with the stationary phase for better separation by which the application of higher column temperature is sometime preferred. Conversely, a low column temperature will cause the entire amount of target analyte to be condensed resulting in poor separation of the target analyte due to a low interaction with the stationary phase (Clark, 2007).
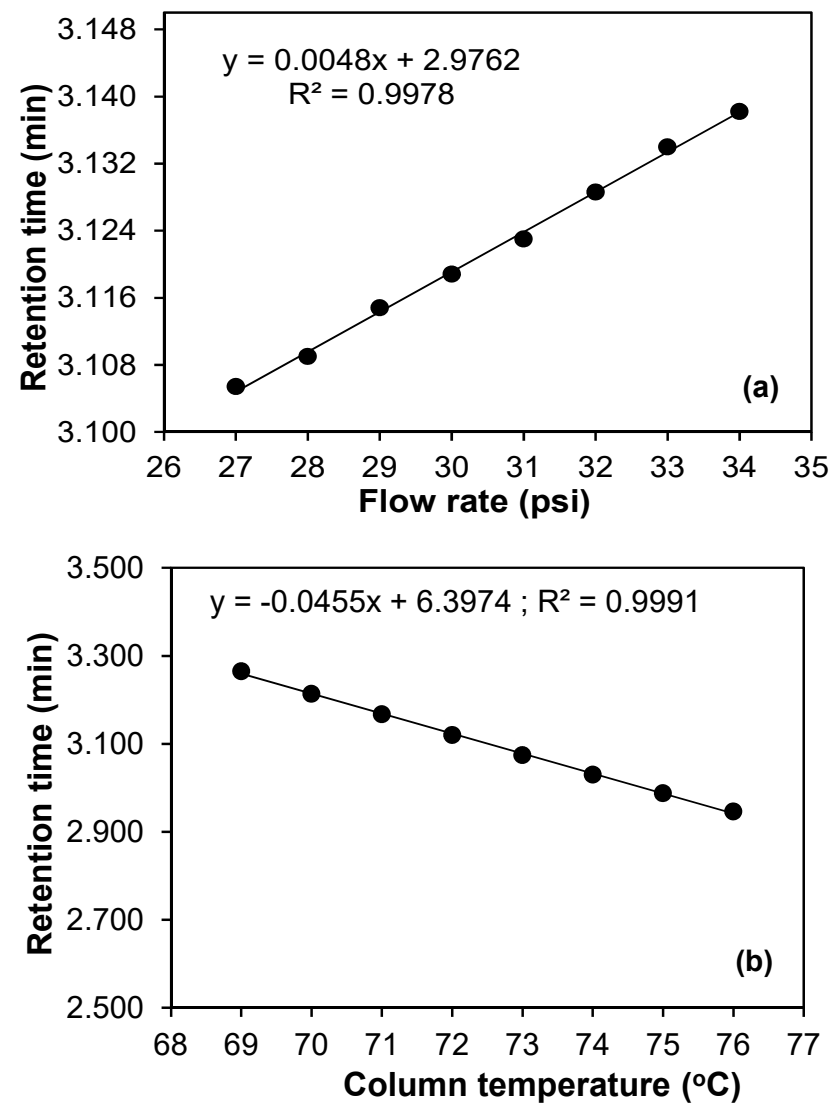

Figure 2. Graphical dependencies of the $t_{R}$ on:

(a) flow rate of carrier gas, and (b) column temperature for the measurement of $S_{6}$ using GC-ECD.

\subsection{Response Factor $\left(R_{F}\right)$}

Some detector respond to any compound eluting from the column while others respond only compound with category or class of compounds having specific structure, functional groups or atom (Yuwono and Indrayanto, 2005; Basuri et al., 2016). Detectors that exhibit response to 
specific or class of compounds are called selective detector (Yuwono and Indrayanto, 2005). One is interested in the ability of the selective detector to detect the characteristics of the target compound while reject everything else. For example, electron capture detector (ECD) can be very selective to halogen-containing compound (Jin et al., 2012). Likely, the response of the gas components that reach the ECD in the GC instrument is similar to other detector types, which is proportional to their size of a spectral peak. Besides the detector response is dependent on the individual target gas component (Dettmer-Wilde and Engewald, 2014). Thus, determination of the response of a gas component in term of its response factor (hereinafter denoted as RF) for a specific detector is highly recommended.

In the GC technique, the RF is defined the ratio between the concentration of an component being analyzed and the response of the detector to that component (Botana, 2015).
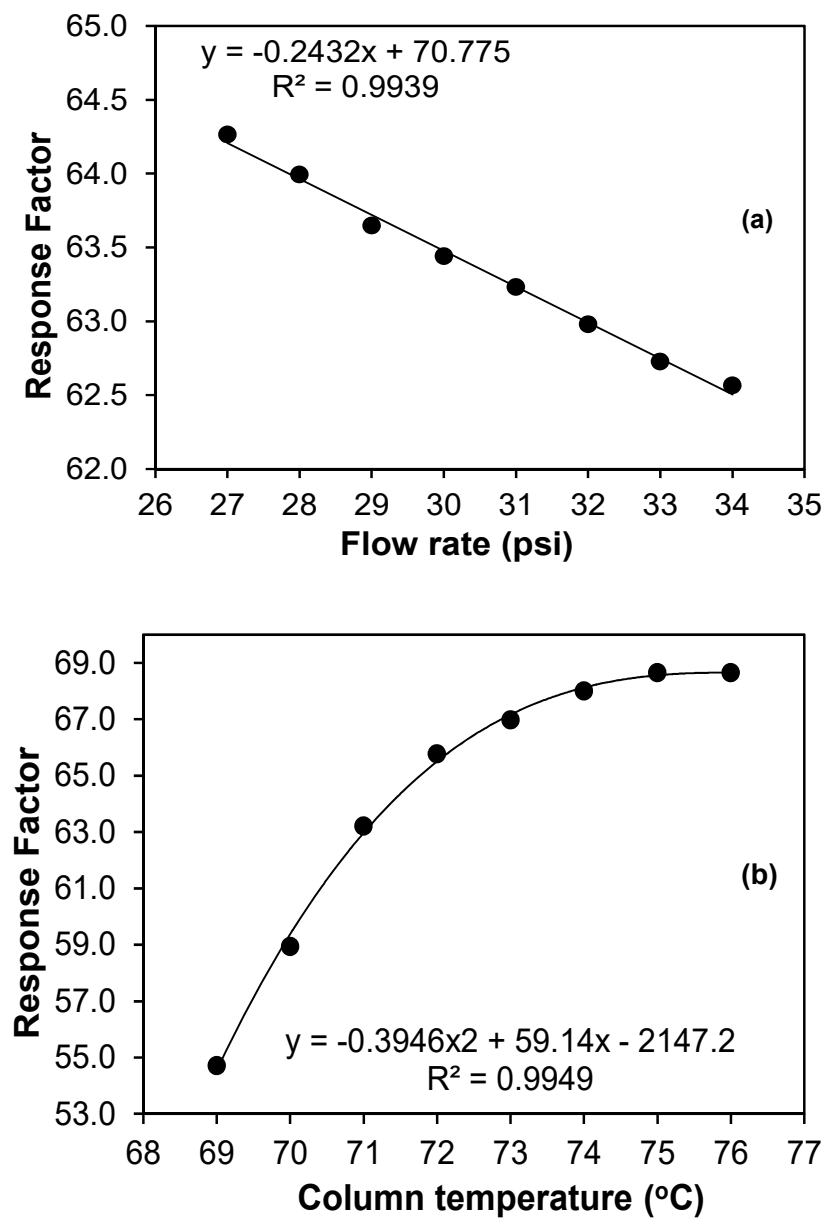

Figure 3. Graphical dependencies of the RF on the flow rate of carrier gas (a) and column temperature (b) for the measurement of $\mathrm{SF}_{6}$ using GC-ECD.
The RF of GC technique can be obtained by measuring a known quantity of component and determining the relevant peak area. The RF of component being analyzed is dependent on the GC operating parameters such as flow rate of carrier gas and column temperature (Onuska and Karasek, 2012). These facts imply that the RF of individual component have to be firstly evaluated experimentally. Figure $3 a$ and $3 b$ present plot of $R F$ of $\mathrm{SF}_{6}$ as a function of the carrier gas flow rate and column temperature, respectively. From Fig. 3a, it can be observed that the RF of the $\mathrm{SF}_{6}$ was found to be decrease linearly $\left(R^{2}=0.9939\right)$ by increasing the flow rate of carrier gas. The response of GC detector is highly proportional to the concentration of component being analyzed, where increase the flow rate can dilute the target component (Cazes, 2005), which may further lower the RF and then decrease the response factor.

Moreover, plot of the RF of $\mathrm{SF}_{6}$ as a function of column temperature is depicted in Fig. $3 b$. Figure $3 b$ clearly confirms that increasing the column temperature up to $72^{\circ} \mathrm{C}$ leads to a significant increase in $R F$ of the $\mathrm{SF}_{6}$ component. However, when the column temperature was greater than $73^{\circ} \mathrm{C}$, the $R F$ of $\mathrm{SF}_{6}$ increases slowly. The trend of the $R F$ of $\mathrm{SF}_{6}$ was found to be second order of polynomial $\left(R^{2}=0.9949\right)$.

\subsection{Number of Theoretical Plate (N)}

Theoretical plate numbers (hereinafter denoted as $N$ ) in gas chromatography is defined as a hypothetical zone in which two phases of a substance (the liquid and vapor phases) establish an equilibrium with each other (Bruner, 1993). Generally, the $N$ in a column can be used to indicate how well the column to separate similar analytes; thus, the $N$ is commonly used to index the columns performance or column efficiency (Gordon, 2013), and it can be calculated using the Eq. 3 . The Eq. 3 explicitly implies that the $N$ is highly correlated with the GC instrument resolution, meaning that changing in the $N$ values may influence the instrument's resolution (Dettmer-Wilde and Engewald, 2014). Figure 4a presents a graphical dependency of the $N$ on the flow rate of carrier gas. From this figure, it can be clearly seen that the $N$ values increase slowly with increasing the flow rate of carrier gas. Taking into account the $N$ definition as in the Eq. 3 , it is noticeable that changes in the retention time and peak width may impact to the $N$ values of the GC. Increase in the peak width of the target analyte at 
constant retention time would decrease the $N$ values, while increase the retention time at a constant peak width lead to increase the $N$ values. In accordance with the Fig. $4 a$, one can be expected that increasing the $N$ values of the GC for the measurement of $\mathrm{SF}_{6}$ might be probably due to increase the retention time (see Fig. 1a) rather than decrease in peak width of the $\mathrm{SF}_{6}$. Because of the $N$ value of the GC-ECD for measurement of $\mathrm{SF}_{6}$ (Fig. 4a) increased with increasing the flow rate $\left(R^{2}=0.9404\right)$; therefore, the efficiency of the column performance of the GC-ECD for $\mathrm{SF}_{6}$ measurement is better at higher than lower flow rate of the carrier gas. In general, high column efficiency in a GC is beneficial to obtain a complete narrow peak which requires less peak separation (Sherma and Zweig, 2013). In practice, however, the column efficiency is highly dependent on many GC operating parameters such as column dimensions (diameter, length and film thickness), the type of carrier gas and its flow rate, as well the compound and its retention time (Bruner, 1993; Dettmer-Wilde and Engewald, 2014).
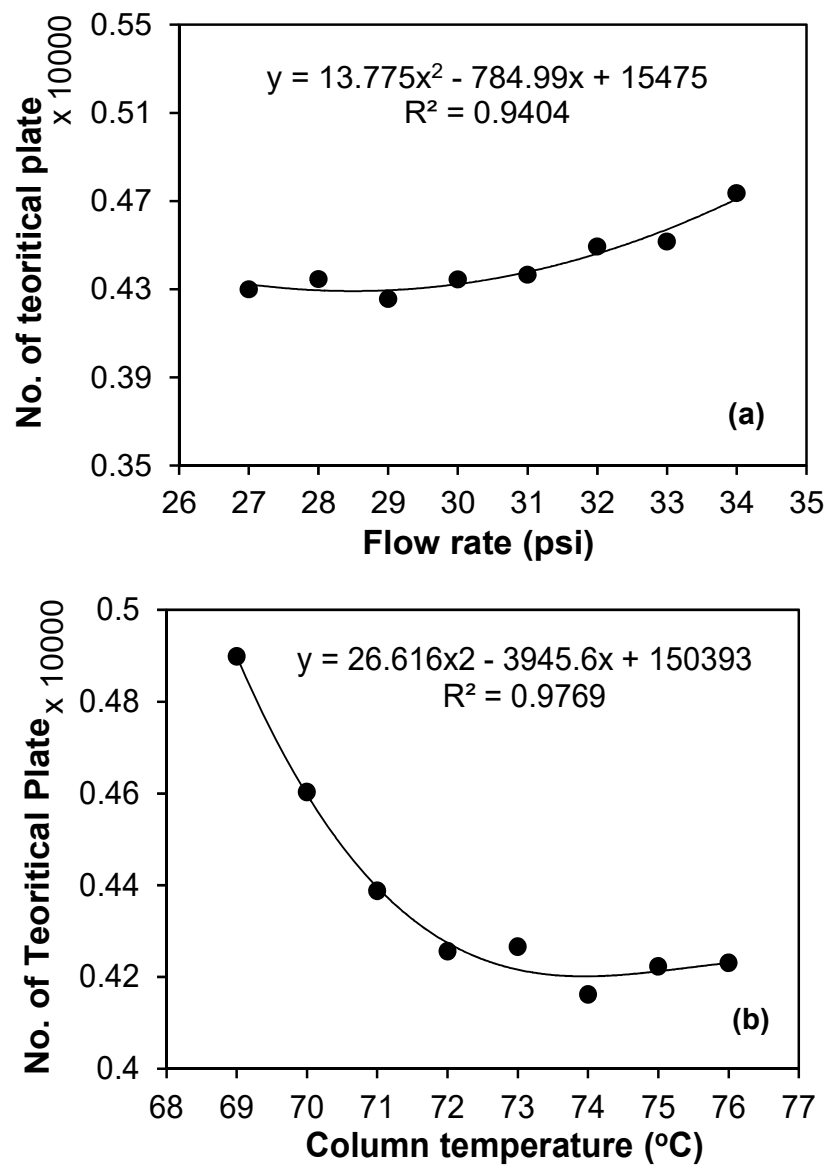

Figure 4. Graphical dependencies of the $\mathrm{N}$ on the flow rate of carrier gas (a) and column temperature (b) for the measurement of $\mathrm{SF}_{6}$ using GC-ECD.
Figure $4 \mathrm{~b}$ displays a graphical trend regarding the $N$ values at different column temperature for the measurement of $\mathrm{SF}_{6}$. As it can be seen for Fig. $4 b$ the $N$ value of the GC significantly decrease with increasing the column temperature up to $72^{\circ} \mathrm{C}$ and then decreasing slowly. This finding indicates that the effectiveness of the column for the $\mathrm{SF}_{6}$ measurement decreases with increasing the column temperature because higher column temperature contributes to the faster elution (shorter retention time) of the $\mathrm{SF}_{6}$. This phenomenon is in agreement with the Fig. 2b, where the $\mathrm{SF}_{6}$ retention time decreased with increasing the column temperature. Decreasing the trend of the $N$ values of the GC-ECD for the $\mathrm{SF}_{6}$ measurement was found to be a second order of polynomial $\left(R^{2}=0.9769\right)$. An isothermal temperature condition of GC column is required since the $N$ value is only valid for a certain temperature point. On the other hands, changes in the temperature of GC column would result in highly inflated, leading to change the $N$ value (Rood, 2007; Hubschmann, 2015).

\subsection{Asymmetry Factor $\left(A_{s}\right)$}

Asymmetric factor (hereinafter denoted as $A_{s}$ ) or tailing factor is a measure of peak tailing of a target analyte being analyzed (McNair and Miller, 2011). In an ideal condition, any chromatographic peaks should be characterized by symmetric (or Gaussian peaks) shape. Experimentally, asymmetric (or tailing) of the GC peak may frequently found due to GC operating condition such as instrument dead-volume, adsorptive effects of the stationary phase, and the quality of the column packing (Rotzsche, 1991; Dettmer-Wilde and Engewald, 2014). Figure 5 shows the effect varying flow rate of carrier gas and column temperature on the $A_{s}$ for the measurement of $\mathrm{SF}_{6}$ by using GC-ECD.

As can be seen in Fig. 5a, any increase in the flow rate of carrier gas gave a small change on the $A_{s}$ of $S F_{6}$ peaks $\left(R^{2}=0.1288\right)$ in comparison to other suitability parameters as discussed above. The curve was tend to form a flat shape, indicating that the flow rate of carrier gas has very small effect on the $A_{s}$ of $\mathrm{SF}_{6}$ peaks. The values of $A_{s}$ at all points of flow rate were found to be slightly higher than the acceptance value and gave asymmetric of $\mathrm{SF}_{6}$ peaks. An acceptable value of $A_{s}$ should be in the range of 0.9-1.2, meaning that the tailing factor would apparent if the $A_{\mathrm{s}}$ value exceeds 1.2 (Cazes, 
2004; Dettmer-Wilde and Engewald, 2014).

Moreover, Figure $5 \mathrm{~b}$ shows the effect of column temperature on the $A_{S}$ of $\mathrm{SF}_{6}$ peak measured using GC-ECD. The $A_{s}$ of $\mathrm{SF}_{6}$ peak was found to be increase slightly by increasing the column temperature up to the first $71^{\circ} \mathrm{C}$, after that any increase in column temperature makes decrease in the $A_{s}$ of the $\mathrm{SF}_{6}$, giving a trend which follows a second order of polynomial $\left(R^{2}=\right.$ 0.9778). This finding implies that the column temperature has an effect on the $A_{s}$ value of $\mathrm{SF}_{6}$, where the $A_{S}$ value of $\mathrm{SF}_{6}$ peak can be difference (decrease or increase) at any point of column temperature. This phenomenon might be correlated to the temperature dependency of the stationary phase to adsorb the $\mathrm{SF}_{6}$, indicating that the value of $A_{s}$ for $\mathrm{SF}_{6}$ measurement can be obtained by altering the column temperature at a certain point.
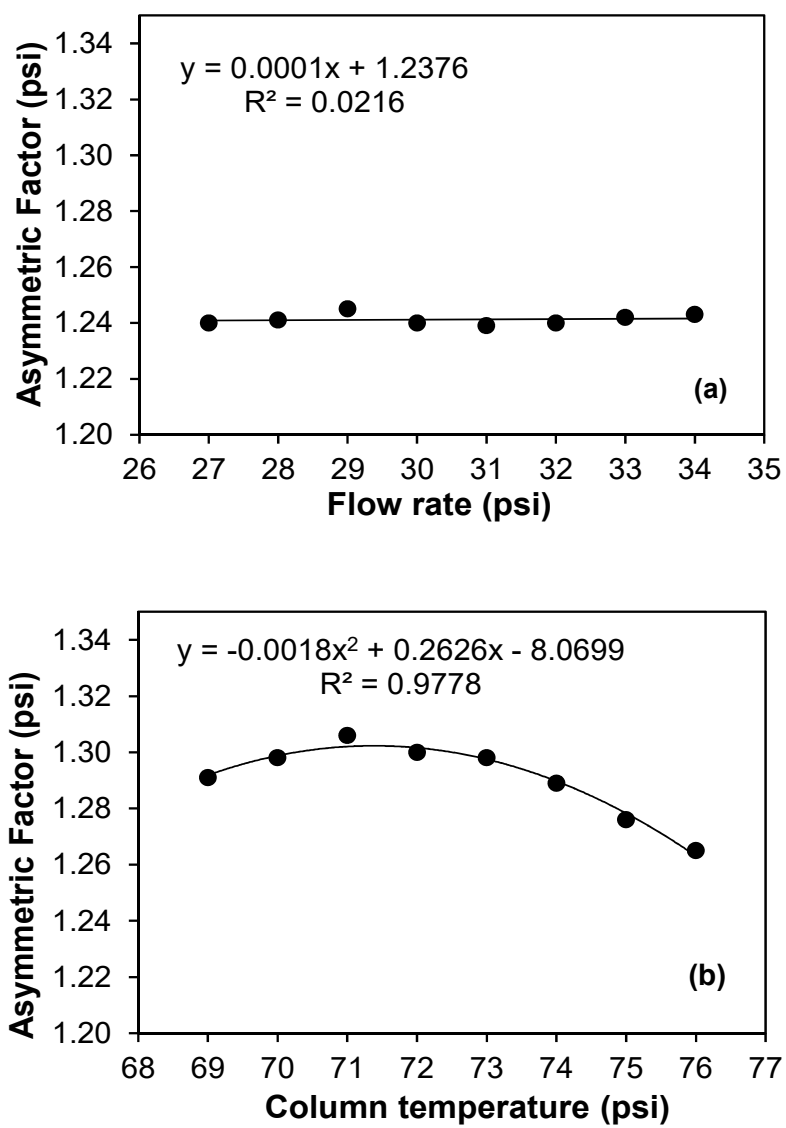

Figure 5. Graphical dependencies of the $A_{s}$ on the flow rate of carrier gas (a) and column temperature (b) for the measurement of $\mathrm{SF}_{6}$ using GC-ECD.

\section{CONCLUSION}

Study the effect of carrier gas flow rate and column temperature on the system suitability parameters of GC-ECD for the measurement of $\mathrm{SF}_{6}$ has been successfully conducted. The effects of flow rate and column temperature on the parameters of the system suitability tests of the chromatography method might be characterized by the interaction properties between $\mathrm{SF}_{6}$ as non polar compound and the stationary phase (column). An important conclusion from this study that investigation regarding the effect of operating condition on the system suitability tests of chromatography method is crucial as an initial step for any chromatographic method application.

\section{ACKNOWLEDGEMENT}

This work was supported by the LIPI's project funded by the Indonesian Government within the scope of "Strengthening Chemical Metrology Competency and Infrastructure" under Project No. SP.DIPA-079.01.2.664833/2016. Ms. Krishna Dian Purnama from Chemical Engineereing Faculty, Diponegoro University for helping in GC-ECD data collection is highly acknowledged.

\section{REFFERENCES}

1. AP. Air Product. Analytical laboratories applications: GC with electron capture detector, 2016, (https://www.airproducts.com/industries/anal ytical-laboratories/). Accessed on 8/7/2016.

2. Balaban, N. E.; Bobick, J. E. The handy science answer book. Visible Ink Press Miami, U.S.A., , 2011, p. 55-92.

3. Banghui, Q. et al., Residual analysis of organochlorine pesticides in soil by gas chromatography-electron capture detector (GC-ECD) and gas chromatograph-negative chemical ionization Mass Spectrometry (GC$\mathrm{NCl}-\mathrm{MS})$. Journal of Environmenta Forensics, 2009, 10(4): 331-335.

4. Barwick, V. J. Sources of uncertainty in gas chromatography and high-performance liquid chromatography. Journal of Chromatography, 1999, 849(1): 13-33.

5. Basuri, T. S. et al., A review on general introduction of comprehansive twodimensional gas chromatography. World Journal of Pharmaceutical Research, 2016, 5(8): 328-343.

6. Bebbrecht, F.J. in: Modern practice of gas chromatography. $3^{\text {rd }}$ ed. R.L. Grob (Ed.). Chichester, Wiley Interscience, New York. U.S.A, 1995, 912p. 
7. Blasing T. J. Recent greenhouse gas concentrations. Oak Ridge National Laboratory, United State Department of Energy, 2016.

http://cdiac.ornl.gov/pns/current_ghg.html)

Accessed on 8/12/2016.

8. Bordagaray, A., et al., A review on microextraction techniques for selected triazole fungicides determination in water and food samples. Journal of Food Chemistry \& Nanotechnology, 2016, 2(3): 128-137.

9. Botana, L. M. Seafood and Freshwater Toxins: Pharmacology, Physiology, and Detection. $3^{\text {rd }}$ Ed., Boca Raton, Florida, TCRC Press, 2015., 1215p.

10. Bruner, F. Gas chromatoraphic environmental analysis: Principle, techniques, instrumentation. VCH Publisher, New York. U.S.A., 1993, 233p.

11. Cazes, J. Encyclopedia of chromatography. Update suplement. Taylor \& Francis. New York. U.S.A., 2004, 376p.

12. Clark, J. Gas liquid chromatography. 2007 (http://www.chemguide.co.uk). Accessed on 23/12/2016.

13. Colon, L. A. and Baird, L. J. Detector in modern gas chromatography. John Wiley \& Sons, New York, 2004, 1064p.

14. Deng, C. et al., A Novel Miniaturized Flame Ionization Detector for Portable Gas Chromatography. Journal of Chromatographic Science, 2005, 43: 355357.

15. Dettmer-Wilde, K.; Engewald, W. Practical gas chromatography: a conprehensive reference. Springer, Heidelberg, 2014, 902p.

16. El-Naggar, A. Y. Factors affecting selection of mobile phase in gas chromatography. American Journal of Research Communication, 2013. 1(3): 219-228.

17. Fang, $\mathrm{X}$. et al., Sulfur hexafluoride $\left(\mathrm{SF}_{6}\right)$ emission estimates for China: An Inventory for 1990-2010 and a projection to 2020. Environmental Science \& Technolog, 2013, 47: 3848-3855

18. Fattahi, N. et al., Determination of chlorophenols in water samples using simultaneous dispersive liquid-liquid microextraction and derivatization followed by gas chromatography-electron-capture detection. Journal of Chromatography $A$, 2007, 1157(1-2): 23-29.

19. Gordon, M. H. Principles and applications of gas chromatography in food analysis. Ellis Howrwood Limited, West Sussex, 2013, $374 p$.
20. Haskin, C.; Edwards, G. Determination of the concentration of atmospheric gases by gas chromatography. McNair Scholars Research Journal, 2013, 6(1): 37-52.

21. Hubschmann, H. J. Handbook of GC-MS: Fundamentals and applications. $3^{\text {rd }}$ Ed., Wiley-VCH. Germany. 2015, 880p.

22. HunterJr, R. E., et al., Method for the determination of organophosphorus and pyrethroid pesticides in food via gas chromatography with electron-capture detection. Journal of Agricultural and Food Chemistry, 2010, 58(3): 1396-1402.

23. ISO. ISO 6142-1:2015: Gas analysis Preparation of calibration gas mixtures - Part 1: Gravimetric method for Class I mixtures. Geneva, Switzerland, 2015.

24. Jin, B., et al. Multi-residue detection of pesticides in juice and fruit wine: A review of extraction and detection methods. Food Research International, 2012, 46: 399-409.

25. Jong, E. C., et al., An ultra-trace analysis technique for $\mathrm{SF}_{6}$ using gas chromatography with negative ion chemical ionization mass spectrometry. Journal of Chromatographic Science, 2015, 53(6): 854-859.

26. McNair, H. M.; J. M. Miller. Basic gas chromatography. $2^{\text {nd }}$ Ed., John Wiley \& Sons, New Jersey, 2011, 256p.

27. Onuska, F. I.; Karasek, F. W. Open tubular column gas chromatography in enviironmental analysis. New York. Plenum Press. 2012, 282p.

28. Pfannkoch, E. A. et al., Multidimensional GC analysis of complex samples. Gersteel Application Note (AN/2005/02), 2005. (http://www.gerstelus.com/media/), Accessed on $8 / 12 / 2016$.

29. Rood, D. The troubleshooting and maintenance guide for gas chromatography. $4^{\text {th }}$ Ed. Wiley-VCH, Weinhem, Germany. 2007, 344p.

30. Rotzsche, H. Stationary phase in gas chromatography. Elsevier Sceince Publishing Company Inc., Amsterdam. The Netherlands, 1991, 408p.

31. Santella, N., D., et al., Atmospheric variability and emissions of halogenated trace gases, Near New York City. Atmospheric Environment, 2012, 47: 533-540.

32. Scott, R. P. W. Chromatographic detectorsdesign, functionand operation, CRC Press, New York, U.S.A, 1996, 536p..

33. Sevcık, J. Detectors in gas chromatography. Elsevier, Amsterdam, 1976. 
34. Sherma, J.; G. Zweig. Formulation analysis in Gas Chromatographic analysis: analytical method for pesticides and plant growth regulator. Vol, 6. Academic Press. Inc. London, U,K., 2013, pp. 107-130.

35. USP37. United State Pharmacopeia: Physical-tests-621/Chromatography. 2016. (https://hmc.usp.org/). Accessed on $12 / 11 / 2016$

36. USP29, United State Pharmacopeia: Chromatography-system suitability. 2016. (http://www.usp.org/), Accessed on 12/11/2016.

37. Wu, P. S., et al., Gas chromatography-mass spectrometry analysis of photosensitive characteristics in citrus and herb essential oils. Journal of Chromatography and Separation Techniques, 2014, 6(1): 1-9.

38. Yu, S., et al., Rapid analysis of cyclamate in foods and beverages by gas chromatography-electron capture detector (GC-ECD). Food Chemistry, 2012, 134(4): 2424-2429.

39. Yuwono, M.; G. Indrayanto. GC system instrumentation in encyclopedia of chromatography, Vol. 1. J. Cazes. Ed., Florida, USA, CRC Press. 2005, pp. 682688.

40. Zuas, O.; Budiman, H. Estimating precision and accuracy of GC-TCD method for carbon dioxide, propane and carbon monoxide determination at different flow rate of carrier gas. Hemijska Industrija, 2016, 70(4): 451459.

41. Zuas, O.; Budiman, $\mathrm{H}$. Flow rate of carrier gas affecting the key parameters of GC-TCD for $\mathrm{CO}_{2}, \mathrm{C}_{3} \mathrm{H}_{8}$, and $\mathrm{CO}$ analysis: an experimental investigation. Teknologi Indonesia, 2016, 39(2): 59-68. 